\title{
Estimation of performances of on-the-farm tested pigs
}

\author{
J. NAVEAU \\ I.T.P., Centre expérimental de Sélection porcine, \\ Maxent, 35380 Plélan-le-Grand (France)
}

The aim of the present study was to establish correction equations for the performances of on-the-farm tested pigs.

A total of 659 gilts and boars of the "Hampshire" and "Pen Ar Lan" lines from the Experimental Selection Centre of I.T.P. were weighed twice at about $20 \mathrm{~kg}$ liveweight and twice a.t about $100 \mathrm{~kg}$ liveweight, each time at intervals of 3 weeks.

Prediction equations for age at $20 \mathrm{~kg}$, age at $100 \mathrm{~kg}$ and for backfat thickness at $100 \mathrm{~kg}$ were established.

The accuracy of these equations ranged about $\mathrm{R}^{2}=0.90$.

It appears that it is advisable to perform weighings and backfat thickness checkings as late as possible.

If the fattening length is considered as the goal of selection rather than the age at about $100 \mathrm{~kg}$, the accuracy of the estimation is much enhanced by weighing the piglets at the beginning of the fattening period.

\author{
III. - Carcass aNl MEAT QUality
}

\section{Use of olfactory tests to detect boar taint in meat from 150 day-old boars}

\author{
M. BONNEAU (1), B. DESMOULIN $\left(^{1}\right)$ et M. PAWLAK (2) \\ (1) Station de Recherches sur l'Elevage des Porcs, \\ I.N.R.A.-C.N.R.Z., $7835^{\circ}$ Jouy-en-Josas (France) \\ ${ }^{(2)}$ Sociét: Duquesne-Purina, Château du Rouvray, \\ 76650 Le Petit-Conronne (France)
}

A total of 165 crossbred young boars were slaughtered at roo $\mathrm{kg}$ live weight and 5 months of age. The olfactory tests of heated fats were performed at the slaughter house and then in the laboratory. Cutlets from a sample of 60 carcasses were used for olfactory tests during cooking followed by gustatory tests.

There was a great difference in the severity of judgment of the 5 panel members. On an average, the judgments of the whole panel can be considered as more severe than those resulting from a consumer's survey. The frequency of very marked boar taint was 7 per cent according to the olfactory tests on heated fats performed in the laboratory and 12-20 per cent during cooking of the cutlets.

The great number of olfactory tests practised after heating of the fats permitted to detect all carcasses liable to present boar taint at the time of cooking. However, in practice, using one or two judges at the slaughter house this test is not reliable. Further tests have to be done in the laboratory.

By means of present methods of boar taint testing it is not possible to rapidly decide if such and such carcass can be sold as fresh pork or not. Tne conditions of male meat testing and use should be defined more accurately. 